\title{
International Public Sector Accounting Standard (IPSAS) in Nigeria as a Correlate to Transparency and Accountability
}

\author{
Innocent Felix Idoko, Susan Peter Teru, Mustapha TafidaAminu \\ Department of Accountancy, Taraba State University, Jalingo, Nigeria \\ Email address: \\ drifidoko@gmail.com (I. F. Idoko)

\section{To cite this article:} \\ Innocent Felix Idoko, Susan Peter Teru, Mustapha TafidaAminu. International Public Sector Accounting Standard (IPSAS) in Nigeria as a \\ Correlate to Transparency and Accountability. Journal of Finance and Accounting. Vol. 6, No. 5, 2018, pp. 110-116. \\ doi: $10.11648 /$ j.jfa.20180605.12
}

Received: September 3, 2018; Accepted: October 19, 2018; Published: November 12, 2018

\begin{abstract}
International Public Sector Accounting Standard (IPSAS) is the version of International Financial Reporting Standardfor meetingcomplex challenges of modern financial reporting. (This is in terms of coherency, consistency, uniformity, internationalization, and clarity in the preparation and reporting standard for public sector financial information. This study is empirical and seeks to determine the correlation between IPSAS implementation and transparency and Accountability in the Nigeria Public sector. A positive correlation will be in consonance with the Accounting theory of fair reporting of the socioeconomic position and performance of practicing organizations. Conclusion can be that transparency and Accountability are being embraced. Consequently, such result justifies the Direct Benefit Theory for instance that direct capital inflow into Nigeria from other IPSAS practicing countries is being facilitated. A hypothesis on the relationship between IPSAS implementation and Transparency and Accountability was formulated. The Central Bank of Nigeria and the Auditor General of the Federation's offices from which 100, and 50 staff randomly selected provided useful information. Primary and secondary data utilized were utilized for this study. Simple percentages were used for ratings in the analysis of data. The hypothesis was tested through the Product - Moment Correlation. Out of 150 respondents, 102 (or 68\%) posited that there is a high correlation between IPSAS implementation and transparency and accountability in IPSAS practicing organizations. Correlation coefficient, $\mathrm{r}$ of 0.20 (or 20\%) obtained implies a Linear relationship. The null hypothesis of no correlation between IPSAS implementation and transparency and accountability was rejected, while the alternative hypothesis was accepted. Conclusion was that $20 \%$ coefficient shows a weak correlation implying the need for complementary independent variables (like increased regulatory framework) as transparency and accountability re-enforcements. It is recommended that more regulatory framework be promoted.
\end{abstract}

Keywords: Accountability, Clarity, Coherency, Consistency, Correlation, Internationalization, Standard, Transparency

\section{Introduction}

\subsection{Introduction}

According to Izedonmi and Ibadin [15], the international Public Sector Accounting Standard (IPSAS) consists of the guidelines for Public Sector Accounting Information. IPSAS is considered to be a reform systemfor providing the basis for quality financial reportingas a way of managing financial resources efficiently. The scarcity of financial resources coupled with frequent global economic crises, notably those of the 2007-2009 financial market met down, the 2009-2012 European debt crises, the Paris Club's crises of the 2000s, the fluctuation in the global Oil market and the manipulations of public finances by leaders, especially in the developing countries, had made the world to search consistently on how to evolve a more acceptable standard of financial reporting. A large number of financial experts under the auspices of International Federation of Accountants (IFAC) formed the International Public Sector Accounting Standard Board (IPSASB) to regulate and establish the standard Accounting practices (SAPs). IPSASB came up with the International Public Sector Accounting Standards. To IPSAS (Nigeria) Sub-Committee Manual [11] IPSAS aimed at standardizing and harmonizing accounting procedures in the Public Sector. IPSAS has become a global idea for instituting Transparency 
and Accountability in governance. The major tenets of IPSAS include high quality, robust and full disclosure of public assets, liabilities and capital aggregation. Nigeria and indeed most parts of the world had kept and embraced the cash Basis Accounting System established by the Finance Control and Management Act of 1958 as amended CAP, A15 LFB 2004. This practice of recording cash inflow when actual cash was received, while expenditures were recorded when actual payments were made did not portray reality. Inadequate disclosure and other manipulation were some deficiencies of the Cash Basis Accounting. According to the Federation Accounting Allocation Committee (FAA) in Treasury [20] and [21] reports, the implementation of IPSAS by Nigeria is a model for transparency and Accountability.

The adoption of IPSAS by the Public Sector in Nigeria is therefore a positive response to the quest for greater transparency and accountability in the management of public finances. In addition; globalization has increased the need for increased global collaboration in international trade and commerce. Hence, a feasible way to install standard is to increase the standard uniformity in financial reporting.

The civil society groups, human right activists, religious leaders, academicians, and humane politicians have raised their voices to the growing concern for the mismanagement and plundering of public funds. This has generated debates and search for feasible ways of securing public funds and investments. Information is a weapon hence IPSAS is a delight for a match towards where the society deserves to be in terms of secured and full disclosure of financial information to enhance transparency and accountability.

IPSAS is very critical to the fair reporting to major stakeholders of investments - investors, tax- payers analysts and the public. It is a global bench mark for financial reporting by giving a better view of the performance, and cash flow position of an entity.

The Crucial features of IPSAS include;

i. Timely preparation and high quality reporting of a crucial based financial reporting.

ii. Timely reporting of not more than six months of audited financial statements.

iii. Timely reporting of Public Sector Budgets and it's appreciation in sufficient manner.

iv. Timely development and reporting of the principles for fiscal management and control.

\subsection{The Statement of Problem}

Over the years, government accounting system in Nigeria which had been on cash basis hardly worked perfectly. This was however contrary to the private sector which has been practicing the accrual basis noted for working perfectly. This shows that there had been many questions relating to under utilization of publication scarce financial resources in Nigeria.

The implication of cash basis accounting system include inadequate disclosure, and hence its high degree of vulnerability and manipulations.
There are too numerous evidences to mention that lack of transparency and accountability in the public sector or in public affairs account for poverty, conflicts and revolutions worldwide. The reverse will be high standard of living, high income and wealth, high literacy level, lower mortality and cognate peace. Many publicParastatals or agents failing in Nigeria need less explanations as thrown open by the challenges of under utilization of public financial resources. Hence, these facts were buttressed by Achua [1] who posits that the 2004 policy decision by Nigeria to embrace the IPSAS was meant to reverse the inadequacy of public financial leakages in Nigeria.

\subsection{The Objectives of the Study}

This review and analytical study seeks to examine the correlation between IPSAS and Transparency and accountability in Nigeria. In addition, it seeks to examine the major constraints to the effectiveness of IPSAS in the Nigerian Public Sector.

\subsection{The Justification for This Study}

The justification for this study lies in the limited areas of study on the implementation of IPSAS. This study fills the gap in the knowledge of the level of the impact of IPSAS on transparency and accountability. The knowledge on IPSAS is limited and this adds value to the creation of awareness of the correlation between the two variables. The gains of IPSAS' full disclosure of financial information can motivate government and its agencies towards viable planning.

This study as a good measure of the implementation and impact of IPSAS creating viable information on the credibility of government financial statements to external bodies like transparency International (TI), IPSAS Donor Organizations likely to partner with Nigeria in Investments. The literature and findings in this study constitute contribution to knowledge for practicing accountant's researchers, and analysts.

The Study is limited to the office of Accountant General of the Nigerian Federation (AGFN), the overall accounting policy making in Nigeria. The office of Auditor General of the Federation (AGF), the sole examiner and financial reporter in the public sector was also studied. IPSAS is a new Concept in Financial Accounting. Hence, honest effort was made by the researchers to obtain genuine data in order to achieve reliable research findings.

\section{Review of Related Literature}

\subsection{Theoretical Framework}

Four major theories guide the motive andpractice of transparency and accountability in the management of financial resources.

\subsubsection{The Accounting Theory}

Accounting Theory revolves round improved and fair collection, organizing, classification, summarizing, 
interpretation and reporting financial affairs of an enterprise. Accounting should conform to periodic review guidelines in manner to giving true and fair view of financial reporting within the obit of the legal and institutional framework. Hence, Kiugu [6] posits that "the pre requisite is that accounting should agree or conform to the basic truth according to which economic system functions. Consequently, it is important that uniformity is maintained in encoding and financial reporting.

\subsubsection{The Commander Theory}

This theory revolves round the owner/controller, owner/manager or owner/Director enterprises where ownership is divorced from controlling. The power and authority to direct the daily affairs of an enterprise must be delegated to the Later who must in turn deliver transparency and accountability. Hence state officials like Ministers, Directors, Advisers etc are acting on the mandates of states. And so, financial reporting such as income statements, and balance sheets are statements of accountability to stake holders. This theory conforms to IPSAS full disclosure principle. In a broad sense, these financial reports are assumed to give the true and fair view of such entities reported on.

\subsubsection{The Economic Theory}

This theory is premised on the benefits of Economic Integration which seeks harmonious relationship, common policies in specific areas, and networking. Hence, Hamisu, [13] Opines that a network theory predicts direct benefits to interacting partners. An IPSAS practicing party gains direct economic and net purchase value of IPSAS standards. This theory presupposes that IPSAS implementing countries have higher expectation of inflow of direct foreign investments. The basic assumption here is that IPSAS has direct network benefits.

\subsubsection{The Theory of Isomorphism}

Isomorphism builds around the assumption of shareable benefits of environmental opportunities. This theory has a shared view of compatibility or antagonizing relationship between an organization and its environment. Coercive isomorphism is an empowerment through influence and legitimacy pressure on the environment by an organization. IPSAS is a direct external stimulus by foreign accounting firms, investors, and donors on its implementing countries to embrace change in entire financial reporting. Buttressing this point, Anwaruddin [5] identified normative isomorphism with collective struggles of similar agitating parties in pursuance of cognitive base, diffused shared orientation and organizational culture. Hence, organizations in industrial classes tend to work with each other with greater harmony.

\subsection{Conceptual Clarity}

\subsubsection{Introduction}

Public sector accounting likened to government accounting is the process of recording, organizing, or classifying, summarizing, analyzing and interpreting financial transactions of government departments, ministries and agents. This implies that government accounting is mainly financial accounting which deals with the receipts, custody and disbursement of public funds, Government accounting aims at presenting or reporting the true and fair view of the collection, management, and disbursement of public funds in consistent manner with government financial regulations (GFR). This function used to be discharged through the cash basis accounting but now shifting to the accrual accounting basis. IPSAS aims at recognizing and accounting for revenue and expenditure irrespective of when cash exchanges hands. By enhancing the quality of financial reporting, transparency and accountability can be enhanced.

\subsubsection{The Concept of Transparency and Accountability Transparency}

Transparency can be Defined a:

i. Reporting of the state of affairs of an organization which depicts truthfulness, and fairness of the practices and culture of the firm.

ii. Clarity in reporting which conforms to the laid down industry, economy, regional country wide or global standard.

iii. Assessing measurable information, creating data or access to the actual prevailing practices, the performance or the output or services, of an individual, or organization.

iv. Financial reporting which portrays the actual position of the happening, the relationship among organizational members, the regulation, rules or policies.

v. Obedience to the dictates of authority, owners or share holders of a firm

vi. Creation of an equitableopportunities among organizational members that are easily discernable

vii. Timely collection, management, and publication of information, data, and budgeting

viii. An organizational practice or guides for decision making which can end in full disclosure of organizational financial dealings to the primary stake holders.

To IMF, transparency is based on four cardinal principles

(a) Clarity in the structure and functions of government, the within government responsibilities and to the governed

(b) Complete and outflow of financial information on routine basis

(c) Adequate information content of public budgeting

(d) Availability of financial data subject to independent auditing

\subsubsection{Accountability}

This on the other hand implies unconditional submission to the scrutiny or performance evaluation of institutional codes. According to Adegbite [2], accountability is the obligation to demonstrate that work performance was accomplished in accordance with the set rules or standard as reported. Accountability consists ofthree folds, namely 
(a) The display of acceptability of one's responsibility for decision making

(b) With the expression of the believe that the right thing was done first by an organizational manager, director or the chief executive.

(c) Display of which can be described as adequate, fair, timely, easily discernable reporting to stake holders. Transparency promotes accountability and vice- versa. Ojiakorin Aminu [4] identified the major bottlenecks to transparency and accountability in Nigerian as ethnicity, religion, corruption, and military hangover. These malaise have further heightened the call for the adoption of IPSAS.

\subsubsection{The Meaning of International Public Sector Accounting Standards (IPSAS)}

IPSAS consists of globally designed financial reporting systems for the application by public sector entities other than government business enterprises (GBES). It is the set of accounting standards issued by the International Public Sector Accounting Standard Board (IPSASB) for public Sector Enterprises.

IPSAS aims at inculcating fiscal discipline through the development of setguidelines for fair and just financial practices and reporting by Public Sector entities. IPSASB aims at enthroning high quality, coherent and transparency desirable in public sector financial reporting.

IPSASB consists of 18 volunteer member countries, among which 15 are from the International Finance and Accounting Cooperation (IFAC) and 3 Public members. In Nigeria, According to the Federal Ministry of Finance and the Office of the Accountant General of the Federation, Abuja [12], IPSASB consists of representatives from the Ministry of Finance, Government Audit institutions, Public practice and the academia. All IPSASB members were appointed through the nomination of IFAC. The 18 IPSASB members are reputable Public Sector Accounting Experts.

IPSAS is a well structured, due process method of financial reporting which allows any articulated public sector inputs. Any standard setting passes through three stages of. (i). Concept paper (CP) (ii) Exposure Draft (ED) (iii) Final Standard (FS)

IPSAS was approved by the Federal Government of Nigeria in 2010 for the Public Sector. This was sequel to the dire need for harmonizing the accounting standard with the International Accounting Regulation. According to Dankwambo [10], the adoption of IPSAS was a revolution of the Financial Control Management Act. Of 1958 Cap. 1990, and Audit Ordinance (Act) 1958 as amended to date.

Carnegie and West [8] described IPSAS as the model for publishing public sector finances as stipulated by the International Treating Agreement. Government Accounting in Nigeria has been the Cash Basis Accounting Standard (CBAS) which recognized revenue or income only when cash was realized, handy and expenses recognized only when physical cash was paid out.

According to Ballogun [6], the Cash Basis Accounting
Standard had its draw backs and that the other extreme form of accounting is the complex but more standard crucial basis Accounting Standard (ABAS). In between these two extremes are; the Modified Cash Basis Accrual Accounting Standard (MABAS). Governments adopt these methods to allow flexibility in practices worldwide. Thus, the practices of each of these methods may be subject to great deal of Judgment and subjectivity.

i. Cash Basis Accounting Standard: Revenues and expenses are recognized only at the point of cash receipt or payment irrespective of the time of transaction.

ii. Accrual Basis Accounting Standard: Transactions are reported in their monetary values as they occur regardless of when cash exchanges hands. Hence revenues are recognized when earned, while expenses are recognized when incurred with or without cash exchanges.

iii. Modified Cash Basis Accounting Standard: Revenues and expenses are recognized only when cash is received or paid. However, it recognizes accruals for short term Balance sheet items i.e as short term financial assets, and liabilities presented on the statement of Assets and liabilities.

iv. Modified Accrual Basis Accounting Standard: Revenues are recognized as they occur and recognized with the exception that expenditures are recognized when incurred, short term assets and liabilities are reported on the statement of Assets and liabilities.

According to Adianric et al. [3], increasing number of government organizations are now using the accrual basis accounting system, with others still using hybrid systems. Like the modified cash accounting, and modified accrual accounting. Over $54 \%$ of countries surveyed in 2014 where still using cash or the modified cash accounting system, while $46 \%$ had adopted the accrual or modified accrual basis.

The adoption of IPSAS accrual basis became popular starting from the 2007 and 2008 global crisis which started in USA due to the collapse of her sub-primary mortgage market, and the subsequent debt crisis.

IPSAS has over 40 standards released through its standard setting procedures

IPSAS indentified recognition, measurement and disclosure requirements. IPSAS'S is standardized format include:

i. Introduction

ii. Objectives

iii. Scope

iv. Accounting Phase

v. Transitional Provisions

vi. Effective Date

vii. Appendices (Implementation guides)

viii. Basis of conclusion

Accrual basis accounting financial statement has the following format

i. Statement of financial position

ii. Statement of financial performance 
iii. Cash flow statements

iv. Statement of changes in asset/equity.

v. Notes to the financial statement.

\section{(i). Worldwide Adoption (WWA) of IPSAS}

According to the IMF (2009) and Malahla (2012)in Aminu [4], in the assessmentof IPSAS's implementation, only seven countries had adopted the full crucial basis of accounting. They includeAustralia, New Zealand, United Kingdom (UK), United States of America (USA), Canada, France and Colombia. As at December $31^{\text {st }}, 2011$, there were 39 countries which started adopting government financial statements on accrual basis, including the USA, UK, Japan, France Canada, Brazil, Switzerland, Australia, and New Zealand, most of them committed to using IPSAS. In addition, most economic blocks or Unions have adopted IPSAS reporting system. More so, Mariano (2015) in Aminu [4], asserted that 40 national governments started embracing IPSAS. Aminu [4] reported that Africa's leading IPSAS users include Nigeria, Ghana, Tanzania, Kenya, Uganda, Rwanda, and Burundi. In Latin America, Chide, Colombia, Brazil, Panama, and Costarica are the leading IPSAS users, in South East Asia, Indonesia, Malaysia and China have adopted full accrual basis IPSAS and strong progress is has started in these countries, especially Cambodia and Vietnam.

\section{(ii). IPSAS Process of Adoption in Nigeria}

According to Caureuing [9], the adoption of IPSAS requires a process Chart of accounts and practical implementation action guide on the relevant financial statements of Ministries and Agencies. The Federal Government of Nigeria (FGN) had a Federal Executive meeting on July $28^{\text {th }}, 2010$, approving that Nigeria adopts the provisions of the international reporting standards (IFRS), and International Public Sector Accounting Standards (IPSAS) by both the private and Public Sectors.

To Ijeoma and Oghoghomeh [14], it was for the dire need for transparency and accountability that the Federation Account Allocation and Fiscal Commission set up an IPSAS Road Map Implementation Committee on $13^{\text {th }}$ June, 2011 with the Following terms;

(1) Provision of road map for adopting IPSAS

(2) Standardizing the National Chart of Accounting (ACOA)

(3) Sensitization of workshop

\section{(iii). IPSAS Accrual Basis Accounting, Transparency and Accountability in Nigeria}

There have been consistent calls around the world for all national governments for transparency and accountability in the management of public financial resource and inits report, Transparency International, (TI) had placed Nigeria as the $145^{\text {th }}$ out of 180 countries studied in 2018 havingbeen left out in the pursuit for holding public officials accountable for their actions while in public offices. In Nigeria too, Obazee [19] reported that there has been increasing pressure on governments at all levels to be more accountable in public sector budgeting. The essence is to produce accurate and adequate transparent financial statements. In Nigeria, several civic society groups have been mounting pressure on governments to embark on full disclosure of its income and expenditure.

Consequently the subcommittee on IPSAS implementation had its membership drawn from experts across the three tiers of government - the Federal State, and Local Government for providing credible road map for the purpose by collaborating with the 36 states of the Nigeria Federation and the Federal Capital Territory of Abuja, as well as the 774 Local Governments. According to Aminu [4], the sub-Committee went ahead to develop a National Chart of Accounts (NCOA) and format of General Purpose Financial Statements (GPFS) cash basis including statutory reports, statistical reports, performance reports and accounting policy as well as a workable templates.

\section{Research Methodology}

This paper is empirical, review and analytical. A few studies have been conducted on the challenges of IPSAS implementation in Nigeria. This one however focuses on the correlation between IPSAS implementation and transparency and accountability in the Nigeria public sector.

Both primary and secondary data were used. The primary data consist of those collected through the questionnaire, and oral interview. Stratified random sampling was used to sample 100 staff of the Central Bank of Nigeria (CBN), and 50 staff of the Auditor General of the Federation (AGF), across randomly selected 10 states (6 states from the North central zone and 4 from North East zone. The secondary data utilized for this study consisted publication in Accounting journals, Newspapers, Workshops/ Conferences, Bulletins, and Annual Reports. Unpublished lectures also formed part of secondary data for this study. Percentage descriptive statistics were used for describing and comparing information generated for analysis. Product -Moment Correlation, was used to test the hypothesis on the relationship between IPSAS implementation and transparency and accountability in the Nigeria public sector.

Product - Moment Correlation, $r=\frac{\sum \mathrm{x} Y}{\sqrt{\left(\sum \mathrm{x} 2\right)\left(\sum \mathrm{Y} 2\right)}}$

Where $\mathrm{r}=$ Product - Moment Correlation coefficient

$\mathrm{X}=$ independent variable (IPSAS Implementation responses by all 150 respondents)

$\mathrm{Y}=$ Dependent variable (Number of responses that IPSAS Implementation enthrones Transparency).

IF $\mathrm{r}=$ Negative, then, there is some negative correlation between IPSAS implementation and transparency and accountability. We can conclude that implementation may not necessarily or completely enthrone transparency and accountability Decision Rule is to accept the null hypothesis.

POSTIVE $\mathrm{r}$ on the other hand is an indication that IPSAS implementation has to an extent enthroned transparency and accountability Decision Rule is to reject null hypothesis and accept alternative hypothesis that IPSAS implementation has a certain degree of correlation with transparency and accountability. 
HIGH VALUE $r$ ie $r>1$ is an indication that IPSAS implementation has significant correlation with transparency and accountability, and if lower than unity, Decision Rule is as in positive $r$.

$$
\text { WhereY }=\mathrm{Y}-\overline{\mathrm{Y}} \text {, and } \mathrm{X}=\mathrm{X}-\overline{\mathrm{X}}
$$

Using vicariate frequency table or distribution, $\mathrm{r}$ can be determined.

\section{Discussion on Findings}

\subsection{Introduction}

All the 150 (or 100\%) respondents provided useful information, and adding that by 2014 Nigeria had adopted IPSAS Cash Basis Accounting while the same number agreed that by 2016, a significant public sector entities had embraced IPSAS Accrual Basis Accounting. A total of 113 (or 75\%) respondents agreed that IPSAS promotes full discourse and also agreeing on it full implementation in 2016 by approximately $75 \%$ of public sector organization in Nigeria. While 96 (or 64\%) of the respondents agreed that IPSAS implementation has enthroned transparency and accountability in Nigeria.

According to the 96 (or 64\%) respondents, IPSAS Accrual Basis Accounting is more coherent, having better disclosure and promoting more transparency in the Nigeria public sector entities. According to 86 (or 57\%) IPSAS implementation in isolation of strong financial regulation can hardly achieve full transparency and accountability. Below is the table on the response of whether or not IPSAS implementation enthrones (correlates with) transparency and accountability in the Nigeria public sector.

Table 1. Whether or not IPSAS implementation correlatives with transparency and accountability in the public sector.

\begin{tabular}{lllll}
\hline S/N & Category (sub-sample) & Number (X) & YES (Y) & No \\
\hline 1 & Policy maker /Executive cared & 10 & 6 & 4 \\
2 & Seniorstaff & 40 & 28 & 30 \\
3 & Middle management cared & 40 & 32 & 12 \\
4 & Clerks & 60 & 10 & 96 \\
& Total & 150 & 54 & 54 \\
\hline
\end{tabular}

Source: Field Survey, 2018

Computation

\begin{tabular}{|c|c|c|c|c|}
\hline $\mathbf{X}$ & $\mathbf{y}$ & $\mathbf{X}^{2}$ & $\mathbf{Y}^{2}$ & $\mathbf{X y}$ \\
\hline$(x-\bar{x})(y-\bar{y})$ & & & & \\
\hline-27.5 & -18 & 756.25 & 324 & -45.5 \\
\hline 2.5 & 4 & 6.25 & 16 & 10 \\
\hline 2.5 & 6 & 6.25 & 36 & 15 \\
\hline 22.5 & 8 & 506.25 & 64 & 180 \\
\hline$\sum x=0$ & $\sum \mathrm{Y}=\mathrm{O}$ & $\sum x^{2}=1275$ & $\sum y^{2} 440$ & $\sum x y=159.5$ \\
\hline$r=\frac{\sum \times Y}{\sqrt{\left(\sum \times 2\right)\left(\sum Y 2\right)}}$ & $r=\frac{159.5}{\sqrt{(1275)(440)}}$ & $r=\frac{159.5}{\sqrt{749}}$ & $r=0.21$ & \\
\hline
\end{tabular}

The correlation coefficients of $21 \%$ show that there is a positive linear relationship between IPSAS implementation and enthronement of transparency and accountability. Hence we reject the null hypothesis that IPSAS implementation has no linear relationship with transparency and accountability.

\subsection{Summary of Findings}

i. There is a linear correlation between IPSAS implementation and transparency in financial reporting $\left(\mathrm{r}={ }^{\text {see }} 0.21\right.$, and table 1$)$ but IPSAS implementation needs reinforcement,

ii. By 2016, approximately $75 \%$ of public sector organizations in Nigeria had embraced IPSAS Accrual basis Accounting (P15 and oral interviewresult)

iii. The challenges of IPSAS in this study corroborated with those of Bello,[7], and Hamisu, [13], Which include (a) Theoretical and conceptual difficultly concerning definition, objectives, Cognizance criteria and its features (b) Infrastructure inability like energy, connectivity, etc. (c) Doubtful capacity in terms of skills, experience, and standard training curricular of training institutions, (d) Financial constraints weakness in the former, Cash accrual system like underestimation of asset.

\section{Conclusions and Recommendations}

\subsection{Conclusions}

The result of test of hypothesis shows that IPSAS implementation can overcome manipulation in specific reporting of income and expenditures. By extension the Accrual Basis Accounting and management decision making can improveefficiency in the management of resources. However IPSAS implementationitself is not sufficient enough to guarantee full transparency without other regulatory reenforcement. The lack of skilled man power, insufficient education, and the inadequate involvement of experts in accounting can stall the effectiveness of IPSAS in Nigeria.

\subsection{Recommendations}

It is recommended that the government continue to redevelop accounting regulatory frame work re-invigorate the development of non-accounting profession, and to enlist the 
support and engagement of enough accountants in public sector entities.

\section{References}

[1] Achua, J. K. (2009). Reinventing Governmental Accounting for Accountability Assurance in Nigeria. Research Journal of Accountancy.

[2] Adegbite, E. O (2010). Accounting, Accountability and National Development. National Accountant 43 (1).

[3] Adianric, Y. Kober R. and Ng. J. (2010). Decision usefulness of Cash and Accrual Information' Public Sector Managers' Perspective Australian Accounting Review 2. 144-153.

[4] Aminu, B. Z. (2018). The International Public Sector Accounting Standard (IPSAS) and the Level of Accountability and Transparency in the Nigeria Public Sector; An Unpublished M.Sc. Thesis, National Open University of Nigeria.

[5] Anwaruddin, C. (2013). Harmonization of Financial Reporting and Audit Practices: Bangladesh Perspective; Dhaka Institute of Chartered Accountants of Bangladesh (ICAB) members' Conference.

[6] Ballogun, E. O, (2010). The Impact of International Public Sector Accounting Standard in the Nigerian Public Sector. International Journal of Advanced Academic Research. 2 (7).

[7] Bello, A. (2013) 'IPSAS: Issues, Challenges and Implementation: Un Published Paper Presentation at the Mandatory Certified Personal Development Organized by the Institute of Certified Public Sector Accountants of Nigeria.

[8] Carnegie, G. D. and West, B. P. (2205). 'Making Accountants Accountable in the Public Sector," Critical Perspectives on Accounting.

[9] Caureuning, H. V (2010)@ International Financial Reporting Standard (IFRS): A Practical Guide ' 6 ' ' ' ed. The World Bank. Washington D. C.

[10] Dankwanbo, I. H. (2010). Transition to International Public Sector Accounting Standard (IPSAS) and Their Impact on Transparency: A Case Study of Nigeria.

[11] IPSAS Sub-Committee. (2015). Accounting Manual / National Chart of Accounts.
[12] Federal Ministry of Finance, Office of Accountant General of the Federation, Abuja, (2013). Training Manual for Workshop for Officers in Public Financial Management for the Three Tiers of Government Federation Account Allocation SubCommittee on Road Map for Adopting IPSAS in Nigeria.

[13] Hamisu, K. S. (2012). Factors Affecting the Implementation of IPSAS in Kenya Unpublished M.Sc Dissertation to the College of Humanities and Social Sciences, University of Nairobi, Kenya.

[14] Ijeoma, N. B. and Oghoghomeh, T. (2014). Adoption of International Public Sector Accounting Standards in Nigeria: Expectations, Benefits and Challenges. Journal of Investments and Managements 3(1).

[15] Izedonmi, F. and Ibadin, P. O. (2013) International Public Sector Accounting Frame Work, Regulatory Agencies and Standard Setting Procedures. A Critique" European Journal of Business and Management.

[16] Kiugu, F. (2010). A Survey of Perception on theAdoptionof International Public Sector Accounting Standard by Local Authorities in Kenya. Unpublished MBA Thesis University of Nairobi.

[17] Lapsley, G. Musari R. and Paulsson, G. (2009). "On the Adoption of Accrual Accounting in the Public Sector; a SelfEvident and Problematic Reform' European Accounting Review. 18/4.

[18] Malahleha, R. (2012). Implications of Adopting and Implementing IPSAS. KPMG Services (PTY) Ltd. A South African Company and Member of the KPMG Network of Independent Member Firms: International Cooperative.

[19] Obazee, J. (2008). 'Public Sector Accounting and Reporting Compliance with Standards' The Nigerian Accountants. 41 (2).

[20] Treasury. (2013). Adoption, Implementation and Application of International Public Sector Accounting (IPSAS) in Nigeria. $13^{\text {th }}$ May, TRY/A4 and B4/2013 DAGF/CAD/026/V.1/190.

[21] Treasury. (2015). Commencement of Implementation of International Public Sector Accounting Standard (IPSAS) Accrual Basis by all Public Sector Entities in Nigeria, $1^{\text {st }}$ $\begin{array}{lll}\text { January, } 2016 . & \text { TRY/48 and }\end{array}$ BB/20150AGF/CAD/026/VOL11/240. 